\title{
La caución en el arbitraje
}

\author{
Fausto Albuja Guarderas* \\ Ana Carolina Donoso Bustamante** \\ Recibido/Received: 07/08/2018 \\ Aceptado/Accepted: 08/08/2018
}

\begin{abstract}
SUMARIO: 1. Introducción. 2. Concepto y finalidad de la caución. 3. Problemas que se generan por la falta de normativa en el tratamiento de la caución. 3.1 La norma no establece la forma en que debe calcularse el monto de la caución. 3.2 No se establece con claridad donde se debe consignar la caución, especialmente en un arbitraje independiente. 3.3 La norma no señala el procedimiento para la devolución de la caución. 3.4 El término para consignar la caución podría ser muy corto especialmente para entidades del sector público. 4. Formas de rendir caución. 4.1 Aspectos importantes a tener en cuenta respecto a las formas de rendir caución. 4.1.1 Disponibilidad inmediata. 4.1.2 Vigencia. 4.1.3 Efectividad independiente. 5. Ejemplos de fórmulas utilizadas. 6. Problema: ¿Qué es "caución suficiente"?. 7. ¿Se puede reglamentar la forma en cómo se debe fijar la caución?. 8. Conclusiones.
\end{abstract}

* Socio de la firma Guarderas \& Guarderas Abogados; Secretario Arbitral del Centro de Arbitraje y Mediación de la Cámara de Comercio de Quito; Miembro del Instituto Ecuatoriano de Derecho Procesal; Docente de la Universidad de las Américas desde el año 2007 hasta la presente fecha y de la Universidad de los Hemisferios desde abril de 2016 hasta junio de 2018. Licenciado en Ciencias Jurídicas y Abogado por la Universidad Católica del Ecuador; Magister en Derecho de Empresa por la Universidad San Francisco de Quito. Correo electrónico: fausto_albuja@hotmail.com

** Socia del Estudio Jurídico Santacruz \& Donoso Abogados; Árbitro de la Cámara de Comercio de Quito y de la Cámara de la Construcción de Quito; Docente de la Universidad San Francisco de Quito en las materias de Derecho Procesal; Docente de la Universidad Andina Simón Bolívar en el Módulo de Métodos Alternativos de Resolución de Controversias de la Maestría en Derecho Procesal; Abogada Magna Cum Laude por la Universidad San Francisco de Quito; Especialista Superior y Máster en Derecho Procesal por la Universidad Andina Simón Bolívar; Candidata a Doctora en Derecho - Phd por la Universidad Andina Simón Bolívar. Correo electrónico: acdonosob@gmail.com 
Palabras Clave: Caución, arbitraje, cálculo, reglamentación.

KEYWORDS: Caution or bond, arbitration, calculation, regulation.

Resumen: La caución es una garantía que se rinde con el objeto de asegurar el cumplimiento de una obligación. Jueces y árbitros en determinadas situaciones deben ordenar la consignación de una caución. En materia arbitral, hay dos situaciones en las cuales los árbitros requieren fijar caución, esto es, cuando la parte contra quien se ha ordenado una medida cautelar pide su suspensión, y cuando quien interpone la acción de nulidad en contra del laudo arbitral, solicita la suspensión de la ejecución del laudo, siendo ésta última situación la que se presenta con mayor frecuencia. Para estos casos, los árbitros no cuentan con una guía o criterio unificado, especialmente respecto al monto de la caución, por lo que tal decisión resulta ser discrecional, lo que en ocasiones afecta los derechos de las partes. El presente artículo pretende abrir el debate, planteando los puntos centrales del tema, en vías a una posible regulación.

Abstract: "Bond is a guarantee that is submitted to ensure compliance with an obligation. Judges and arbitrators in certain situations must order the deposit of a bond. In arbitration, there are two situations in which arbitrators need to set a bond, which are, when the party against whom a precautionary measure has been ordered asks for its suspension, and when the person bringing the nullity action against the arbitration award, requests the suspension of the enforcement of it, the latter being the one that occurs most frequently. For these cases, arbitrators do not have a unified guide or criteria, especially regarding the amount of the bond, which in occasions results on discretionary decisions that sometimes affects the rights of the parties. This article aims to open the debate, raising the central points of the issue, in the way of possible regulation. 


\section{INTRODUCCIÓN}

En el sistema legal ecuatoriano no existe normativa, ni guía, ni uniformidad de criterios para establecer los parámetros que deben seguir los juzgadores al momento de establecer el monto de la caución, cuando en el proceso se requiere asegurar el cumplimiento de determinadas obligaciones derivadas del mismo. Esto significa un problema tanto para los juzgadores, como para las partes, pues la decisión que al respecto tome el juez, puede resultar perjudicial para ellas y afectar el interés de la justicia.

La materia arbitral, no es la excepción. Con frecuencia los árbitros se ven abocados a fijar una caución cuando la parte, dentro del proceso arbitral, ha planteado una acción de nulidad del laudo, y dentro de su petición, ha solicitado la suspensión de la ejecución del laudo o cuando la parte contra quien se ha dictado una medida cautelar, requiere su suspensión. No existe claridad sobre los aspectos básicos para la fijación de la caución por parte de los árbitros, lo que plantea un problema de orden práctico con graves consecuencias. La falta de normas claras al respecto o al menos directrices que puedan guiar a los árbitros en esta tarea, ha tenido como consecuencia que en el ejercicio se hayan adoptado distintas prácticas que en ciertos casos podrían afectar a las partes.

En el presente estudio se busca hacer un acercamiento al tema y presentar, dentro del contexto de la escasa normativa existente, las prácticas comúnmente utilizadas por los árbitros al fijar la caución, cuando la parte que plantea acción de nulidad, solicita la suspensión de la ejecución del laudo. Así, se analizará el concepto de caución y su finalidad, algunos de los problemas que la falta de normativa puede generar en el tratamiento de la caución, las formas de rendir la caución, y se revisarán algunos aspectos importantes a tener en cuenta sobre dichas formas, además de los parámetros que utilizan en la práctica los árbitros para establecer el monto de la caución. Finalmente, se buscará responder a dos cuestionamientos sobre el tema: ¿qué es "caución suficiente"? y ¿se puede reglamentar la forma cómo se debe fijar la caución? 


\section{CONCEPTO Y FINALIDAD DE LA CAUCIÓN}

El artículo 31 del Código Civil ecuatoriano señala que "[c]aución significa generalmente cualquiera obligación que se contrae para la seguridad de otra obligación propia o ajena. Son especies de caución la fianza, la prenda y la hipoteca". Por su parte, de acuerdo al diccionario de la Real Academia Española, caución significa "[g]arantía que presta una persona u otra en su lugar para asegurar el cumplimiento de una obligación actual o eventual"1.

La finalidad de la caución, en el ámbito legal, es otorgar una garantía que sirva para asegurar el cumplimiento de una determinada obligación, que en el contexto de este análisis, se encuentra contenida en una sentencia ${ }^{2}$ o laudo arbitral, según corresponda. En efecto, en el arbitraje, la fijación de la caución se produce cuando la parte que plantea una acción de nulidad contra el laudo arbitral, solicita que se suspenda la ejecución del laudo, mientras se tramita dicha acción ante el Presidente de la Corte Provincial ${ }^{3}$.

1. Real Academia Española, Diccionario, <http://dle.rae.es/?id=7z4jpFL>, (24/07/2018).

2. Código Orgánico General de Procesos (COGEP), Art. 271, RO Sup. No. 506, 22/05/2015.

Art. 271.- "El recurrente podrá solicitar, al interponer el recurso, que se suspenda la ejecución de la sentencia o auto recurrido, rindiendo caución suficiente sobre los perjuicios estimados que la demora en la ejecución de la sentencia o auto pueda ocasionar a la contraparte. El Tribunal correspondiente establecerá el monto de la caución al momento de expedir el auto que califica la oportunidad del recurso, en el término máximo de tres días desde su presentación. Si la caución es consignada dentro del término de diez días posteriores a la notificación del auto de calificación del recurso, se dispondrá la suspensión de la ejecución de la sentencia o auto. En caso contrario, se ordenará su ejecución".

3. Como se ha mencionado, en arbitraje también existe la posibilidad de que, contra quien el Tribunal Arbitral ha dictado una medida cautelar, rinda caución para suspender tal medida conforme lo previsto en el artículo 9 de la Ley de Arbitraje y Mediación, que dispone: "Los árbitros podrán dictar medidas cautelares, de acuerdo con las normas del [COGEP] o las que se consideren necesarias para cada caso, para asegurar los bienes materia del proceso o para garantizar el resultado de éste. Los árbitros pueden exigir una garantía a quien solicite la medida, con el propósito de cubrir el pago del costo de tal medida y de la indemnización por daños y perjuicios a la parte contraria, si la pretensión fuera declarada infundada en el laudo. La parte contra quien se dicte la medida cautelar podrá pedir la suspensión de ésta, si rinde caución suficiente ante el tribunal. Para la ejecución de las medidas cautelares, los árbitros siempre que las partes así lo estipularen en el convenio arbitral, solicitarán el auxilio de los funcionarios públicos, judiciales, policiales y administrativos que sean necesarios sin tener que recurrir a juez ordinario alguno del lugar donde se encuentren los bienes o donde sea necesario adoptar las medidas. [...]".

La situación referida se presenta en la práctica con menos frecuencia que la señalada en el texto, por lo que el presente estudio se centrará a analizar aquella, esto es, la caución que se rinde con la finalidad de que se produzca la suspensión de la ejecución del laudo arbitral hasta que se resuelva la acción de nulidad. 
La Ley de Arbitraje y Mediación en su artículo 31, establece que:

Quien interponga la acción de nulidad, podrá solicitar al árbitro o tribunal arbitral que se suspenda la ejecución del laudo, rindiendo caución suficiente sobre los perjuicios estimados que la demora en la ejecución del laudo pueda causar a la otra parte. El árbitro o tribunal arbitral, en el término de tres días, deberán fijar el monto de la caución, disponiendo la suspensión de la ejecución del laudo. La caución deberá constituirse dentro del término de tres días, contados a partir de esta notificación (énfasis añadido) $)^{4}$.

Por lo dicho, la figura de la caución sirve para garantizar el eventual cumplimiento de la obligación resultante del laudo, cuando éste establece la ejecución de obligaciones de dar, hacer o no hacer, dependiendo el caso ${ }^{5}$. Entendiendo a ésta como la función principal de la caución, se pueden pensar dos funciones adicionales de la caución. En primer lugar, la caución sirve además para resarcir el daño que la demora en la ejecución del laudo, pueda provocar a quien obtuvo un laudo favorable, conforme lo reconoce expresamente la norma de la Ley de Arbitraje y Mediación citada anteriormente. Y, en segundo lugar, aún cuando no sea una finalidad expresamente reconocida, se puede entender que la caución en cierta medida tiene como efecto desincentivar el uso abusivo de la acción de nulidad. En otras palabras, en cierta medida la figura de la caución evita que se pretenda utilizar a la acción de nulidad, como mecanismo para dilatar el cumplimiento de la obligación declarada en laudo, pues el planteamiento de dicha acción, no suspende por sí mismo la ejecución del laudo, sino a través de la caución.

4. Ley de Arbitraje y Mediación (LAM), Art. 31, RO No. 417, 14/12/2006.

5. La Ley de Conciliación y Arbitraje de Bolivia, no establece expresamente la figura de la caución para suspender la ejecución del laudo arbitral. Sin embargo, en el numeral II del artículo 114 señala: "La autoridad judicial cuando se le solicite la nulidad del Laudo Arbitral, podrá suspender la ejecución del Laudo Arbitral, cuando corresponda y así lo solicite una de las partes, por el plazo que estime pertinente, a fin de dar a la o el Árbitro Único o al Tribunal Arbitral la oportunidad de reanudar las actuaciones arbitrales o adoptar cualquier otra medida que a su juicio elimine las causas que motivaron el recurso de nulidad del Laudo Arbitral".

Ley de Conciliación y Arbitraje de Bolivia, Art. 114(11), Ley No. 708, 25/06/2015. 
Asimismo, la norma señalada, únicamente menciona los siguientes aspectos en relación con la caución: (i) el interesado debe solicitar la suspensión del laudo cuando interponga la acción de nulidad; (ii) la caución se refiere a los perjuicios estimados en la demora en la ejecución del laudo; (iii) el tribunal arbitral deberá fijar la caución mediante providencia en el término de tres días; y, (iv) la caución debe rendirse en el término de tres días. Sin embargo, tal como lo revisaremos a continuación, lo expuesto no es suficiente para el tratamiento de la caución, generándose una serie de dificultades e interrogantes que aún no han podido ser resueltas de manera definitiva.

\section{Problemas que se generan por la falta de NORMATIVA EN EL TRATAMIENTO DE LA CAUCIÓN}

Si bien en el acápite anterior se estableció cual es la finalidad de la caución en el arbitraje, sobre lo cual no hay dificultad alguna, es preciso señalar que de la lectura del artículo 31 de la Ley de Arbitraje y Mediación antes citado, existen algunos problemas en el tratamiento de la caución que no han tenido solución definitiva. Como veremos más adelante, los tribunales arbitrales han optado por diversas decisiones para dar viabilidad a algunos de estos problemas.

Se pueden identificar al menos los siguientes problemas: (i) la norma no establece la forma en que debe calcularse el monto de la caución ${ }^{6}$; (ii) no se establece con claridad donde se debe consignar la caución especialmente en un arbitraje independiente;

6. Tal como lo reseña S. ANDRADE en su libro La Casación Civil en el Ecuador, este problema no se presenta sólo en el arbitraje, pues en casación tampoco existe normativa alguna que regule los parámetros para fijar la caución. “A pesar de los años transcurridos, la Corte Suprema de Justicia no ha dictado el instructivo que deberían seguir los tribunales para el perjuicio de la demora. Los tribunales de instancia proceden con innegable discrecionalidad en este campo, unas veces fijan cauciones excesivamente elevadas, lo que imposibilita el que se las constituyan y colocan a los recurrentes en imposibilidad de alcanzar la suspensión de la ejecución de la sentencia o auto recurrido; en otros casos, en cambio, señalan cauciones mínimas. Esta discrecionalidad extrema indudablemente atenta contra la seguridad jurídica".

S. ANDrade, La Casación Civil en el Ecuador, Ed. Andrade \& Asociados, Universidad Andina Simón Bolívar, 2005, p. 267. 
(iii) la norma no señala el procedimiento para la devolución de la caución; y, (iv) el término para consignar la caución podría ser muy corto especialmente para entidades del sector público.

\subsection{La norma no establece la forma en que debe calcularse el monto de la caución}

En lo que tiene que ver con el primer punto, el artículo 31 de la Ley de Arbitraje y Mediación únicamente establece como parámetro de cálculo "[...] los perjuicios estimados que la demora en la ejecución del laudo pueda causar a la otra parte". Al respecto, hablar de perjuicios estimados resulta una fórmula demasiado general que ha obligado a los tribunales arbitrales a utilizar distintas formas para fijar la caución.

La decisión que debe tomar el tribunal arbitral al momento de fijar el monto de la caución, resulta muy compleja, considerando que el principal parámetro es un tanto subjetivo y existen elementos muy variables a tener en cuenta.

El principal parámetro a considerar, al momento de establecer el monto de la caución, es la razonabilidad. Como se ha dicho, lastimosamente éste es un término que fácilmente cae en la consideración de criterios subjetivos, pues resulta muy difícil establecer el monto justo o adecuado para ambas partes. Así, no es fácil establecer una caución "razonable", sin que el árbitro caiga en criterios un tanto subjetivos.

En este contexto, los parámetros que comúnmente se utilizan por parte de los tribunales arbitrales son el tiempo que puede demorar el trámite de la acción de nulidad y la cuantía de la condena. Respecto al primer parámetro señalado, esto es el tiempo de demora, cabe señalar que aun cuando la norma del artículo 31 de la Ley de Arbitraje y Mediación señala que el presidente de la Corte Provincial debe resolver la acción de nulidad en el término de treinta días, esto no se cumple y en la práctica, el tiempo de demora en la tramitación de la acción de nulidad es un tanto incierto. 
En la práctica, el término señalado en la ley para la resolución de la acción de nulidad no se cumple, pues resulta irreal en vista de la carga de trabajo que tiene la Corte Provincial ${ }^{7}$.

En relación con el segundo parámetro señalado, esto es la cuantía de la condena, es importante tener en cuenta que resulta inaplicable cuando las obligaciones derivadas del laudo son de hacer, como podría ser por ejemplo la entrega de un bien.

Un ejemplo de cómo un tribunal arbitral ha fijado una caución utilizando los parámetros señalados, es el que aparece en el juicio de nulidad del laudo arbitral No. 070-2014-17100. En este caso, los miembros del tribunal arbitral ordenaron lo siguiente:

[...] 2.1. Que el monto de la caución de USD \$ 244,711.80 fue establecido tomando como base el valor total del adeudo a la compañía XXXXXX que es USD \$974,798.14.- Por ello, y sobre la base de su atribución establecida en el Art. 31 de la Ley de Arbitraje y Mediación este Tribunal ha estimado que los perjuicios que soportaría la compañía $X X X X X X X$ por la demora en el reintegro de valores adeudados, corresponderían al costo financiero de dicho valor, criterio que se ha aplicado no solamente en el caso que refirió XXXXXX en el escrito que se manda agregar, sino en un sinnúmero de otros casos. Por ello, el Tribunal Arbitral mantiene tal criterio, difiriendo en el tipo de interés aplicable y en el tiempo respecto del cual debe ser calculado ese interés;

2.2. Que para estimar los posibles daños derivados de la demora en la ejecución del laudo arbitral, se ha tomado la tasa de interés legal establecida por el Banco Central del Ecuador para el mes de julio de 2011 y que fue del 8,33\%, calculado sobre el valor de USD $\$ 974,798.14$ sobre un periodo de 36 meses y no de 18 meses solamente. El periodo más amplio comprenderá el estimado para resolver la acción de nulidad, (tomando en cuenta

7. Cuando entró en vigencia el COGEP, la Corte Provincial suspendió la tramitación de las acciones de nulidad hasta tener una resolución que le guiara sobre la forma de tramitar la acción de nulidad, ante la vigencia de la nueva norma. En consecuencia, habiendo entrado en vigencia el COGEP el 22/05/2016, la Corte Nacional emitió la resolución No. 08-2017, estableciendo las Reglas para el trámite de la acción de nulidad de laudo arbitral, y es recién en ese momento que la Corte Provincial tiene un fundamento para la tramitación de dicha acción, y retoma la tramitación de las acciones de nulidad que se encontraban represadas por un año, con la consecuente demora de todos esos trámites. Corte Nacional de Justicia, Resolución No. 08-2017, 22/03/2017. 
los registros del Centro de Arbitraje y Mediación de la Cámara de Comercio de Quito que establece ese promedio de un año y medio, más 18 meses adicionales por cuanto se ha reiterado una práctica de interponer, contra las sentencias de la Corte Superior, recursos de casación y, posteriormente, acciones de protección ante el Tribunal Constitucional;

2.3. Que el análisis anterior lo ha hecho este tribunal arbitral con el voto conforme de todos sus miembros y no solamente de uno de ellos y por ello, ratificamos que en el señalado periodo de 36 meses, también se ponderó el contexto de reorganización de la administración de justicia que podría provocar retrasos aún mayores a los que ordinariamente se comprometerían en el trámite de la acción de nulidad (énfasis añadido) ${ }^{8}$.

En el caso mencionado, el tribunal arbitral estimó los perjuicios utilizando dos elementos: (i) el costo financiero del valor de la condena, y (ii) el tiempo estimado para resolver la acción de nulidad, utilizando para su cálculo los registros del Centro de Arbitraje y Mediación de la Cámara de Comercio de Quito, en cuanto al tiempo que demora dicha resolución y el hecho de que en la práctica se interponen recursos sobre la sentencia de la Presidencia de la Corte Provincial ${ }^{9}$.

En otro caso ${ }^{10}$, un tribunal arbitral conformado en un Centro de Arbitraje de la ciudad de Esmeraldas, señaló:

[...] En el término de 3 días rindan caución suficiente garantizando los daños y perjuicio [sic] que la demora de la ejecución del laudo arbitral pueda causar a la otra parte, el valor de la caución es de USD 459.440,76/100. Tal como lo determina el Art. 31 de la Codificación a la Ley de Arbitraje y Mediación $[\ldots]^{11}$.

8. Laudo arbitral No. 070-2014-17100.

9. Cabe aclarar que a partir de la Resolución No. 08-2017, la Corte dispuso: “Art. 4.- De la sentencia que dicte la o el Presidente de la Corte Provincial, no habrá recurso alguno, salvo los recursos horizontales de aclaración o ampliación". Se aclara que el caso señalado como ejemplo es anterior a esta resolución. Corte Nacional de Justicia, N. 6, Art. 4.

10. En este caso la entidad pública interpuso equivocadamente una acción de protección en contra del laudo arbitral, la misma que fue conocida por la Unidad Judicial Penal de Esmeraldas; la causa fue signada con el número 2018-00377.

11. Proceso Arbitral No. 001-2017. 
Como se puede apreciar del párrafo precedente, no existe motivación alguna que justifique dicho monto, más allá de señalar que esto garantizaría los daños y perjuicios por la demora en la ejecución. Lo más preocupante del caso fue que de manera subjetiva y arbitraria, el valor de la condena fue exactamente el mismo que el tribunal arbitral señaló como caución y siendo que la entidad pública demandada no caucionó el valor señalado por el tribunal arbitral, éste resolvió lo siguiente:

[...] por cuanto los recurrentes, no dieron cumplimiento a lo dispuesto por este tribunal en decreto de 21 de diciembre del 2017, a las 11 h10 es decir, no rindieron caución suficiente, por los perjuicios estimados que en la demora de la ejecución del laudo pueda causar a la otra parte contraviniendo la disposición legal prevista en la letra e), inciso cuarto del Articulo 31 de la Ley de Arbitraje y Mediación; y lo dispuesto por la Corte Constitucional del Ecuador, en sentencia No. 007-16-SCM.CC, CASO No. 0141-14-CN, este Tribunal Arbitral amparado en las Normas Legales y Constitucionales citadas; y en el precedente constitucional antedicho, niega los recursos de nulidad, interpuestos por el demandado $[\ldots]^{12}$.

Así, el tribunal arbitral negó la acción de nulidad por no haberse rendido la caución que había dispuesto, considerando que supuestamente se vulneró la ley, desconociendo de este modo la finalidad de la caución y evidentemente afectando los derechos de una de las partes.

Como se puede ver en los casos referidos, marcando la enorme distancia entre el primero y el segundo, resulta indispensable regular de manera inmediata la forma en que se debe calcular la caución, pues, puede pasar como en los casos mencionados, que por un lado, un tribunal arbitral fundamente su decisión en la normativa -independientemente de estar o no de acuerdo con la misma- y por otro, como sucedió en el segundo caso, un tribunal sin conocimiento sobre la materia, perjudique a la parte que interpuso correctamente una acción de nulidad. 
Adicionalmente, dado que no existen lineamientos básicos sobre el tema, puede suceder que otros tribunales tengan criterios distintos y dependiendo del caso, utilicen otros elementos para fijar la caución. Más adelante se analizarán otros ejemplos de cómo se ha fijado la caución en distintos casos.

\subsection{No se establece con claridad donde se debe consignar la caución, especialmente en un arbitraje independiente}

En cuanto al segundo punto, referente a la falta de claridad del artículo 31 de la Ley de Arbitraje y Mediación en relación a la consignación de la caución, especialmente en un arbitraje independiente, es necesario señalar que es un tema que no ha sido desarrollado. La razón podría fundamentarse, en que en el Ecuador, la mayoría de arbitrajes son administrados, por lo que no se ha presentado la necesidad de debatir el tema ampliamente.

Si bien la Ley de Arbitraje y Mediación no señala nada al respecto, los reglamentos de algunos centros de arbitraje si lo hacen $^{13}$. Por ejemplo, el reglamento del Centro de Arbitraje y Mediación de la Cámara de Comercio Ecuatoriano Americana en su artículo 66 dispone que dicha cámara será la custodia de la caución en la forma como fuere consignada. Asimismo, el Reglamento de Arbitraje del Centro de Arbitraje y Mediación de la Cámara de Comercio de Guayaquil, en su artículo 26 dispone:

Cuando se haya solicitado la suspensión de la ejecución del laudo por haberse interpuesto acción de nulidad, el tribunal fijará la caución teniendo en cuenta los perjuicios estimados que la demora en la ejecución de lo ordenado en el laudo pueda irrogar a la parte vencedora del arbitraje. La caución se constituirá a favor de la Cámara de Comercio de Guayaquil, quien dispondrá su entrega a quien corresponda, una

13. Revisados los reglamentos del Centro de Arbitraje de la Cámara de Comercio de Quito, del Centro Internacional de Arbitraje y Mediación de la Cámara de Industrias y Comercio Ecuatoriano Británica y de Industrias y Producción (CIAM) y del Centro Nacional de Mediación y Arbitraje de la Cámara de la Industria de la Construcción (CENAMACO), se verifica que no cuentan con normativa específica relacionada con el tratamiento de la caución. 
vez ejecutoriada la sentencia que resuelva la acción de nuli$\operatorname{dad}^{14}$.

Por su parte, el Reglamento Modelo del Instituto Ecuatoriano de Arbitraje, en su artículo 37 ha tratado de prever todos los aspectos relacionados al tema de la siguiente manera:

Suspensión de los efectos del laudo.

1. Cuando se haya solicitado la suspensión de la ejecución del laudo por haberse interpuesto acción de nulidad, el tribunal fijará la caución teniendo en cuenta los perjuicios estimados que la demora en la ejecución de lo ordenado en el laudo pueda irrogar a la parte vencedora del arbitraje.

2. Las cauciones que podrán rendirse son:

a. Garantía incondicional, irrevocable y de cobro inmediato, otorgada por un banco, o institución financiera, establecidos en el país o por intermedio de ellos;

b. Fianza instrumentada en una póliza de seguros, incondicional e irrevocable, de cobro inmediato, emitida por una compañía de seguros establecida en el país;

c. Efectivo o Cheque Certificado de una institución financiera establecida en el país consignado en la Cámara XX, que deberá ser depositado en una cuenta de la misma.

3. La caución se constituirá a favor del vencedor del arbitraje y se entregará a la Cámara $X X$, quien dispondrá su entrega a quien corresponda, una vez ejecutoriada la sentencia que resuelva la acción de nulidad.

4. La caución deberá ser constituida en el término establecido por el Tribunal Arbitral para estos efectos. Este término podrá ser prorrogado a solicitud motivada de parte.

5. La caución rendida deberá ser renovable automáticamente antes de su vencimiento o a la sola solicitud del Centro. De no ser renovada la caución esta se efectivizará y la Cámara tendrá los fondos disponibles hasta cuando se resuelva la acción de nulidad.

6. Una vez resuelta la acción de nulidad la caución será devuelta:

a. Al vencedor del arbitraje, si la acción de nulidad fuera rechazada.

14. Reglamento de Arbitraje del Centro de Arbitraje y Mediación de la Cámara de Comercio de Guayaquil, Art. 26. 
b. Al proponente de la acción de nulidad, si la acción de nulidad fuera aceptada, total o parcialmente ${ }^{15}$.

De este modo, algunos reglamentos plantean que la cámara a la que pertenecen los centros de arbitraje será el custodio de las cauciones rendidas.

Sin embargo, resulta evidente la dificultad que se presenta con relación a los arbitrajes ad-hoc o independientes. Considerando que el tribunal arbitral pierde competencia luego de haber dictado el laudo arbitral, cabe preguntarse: ¿es correcto que el tribunal sea custodio de la caución? Al respecto, si bien el tribunal pierde facultades jurisdiccionales al momento de dictar el laudo, las facultades administrativas que adquiere al momento de su constitución, aceptación del cargo y declaratoria de competencia, deben mantenerse hasta cuando haya culminado su labor, pues es necesario, especialmente en arbitrajes $a d-h o c$, tener en cuenta las facultades residuales de los árbitros ${ }^{16}$. Lo mismo sucedería con el secretario que fuera nombrado para el caso, quien mantiene sus facultades para atender casos específicos que se producen, tiempo después de dictado el laudo arbitral. En consecuencia, no existe limitación alguna para que el tribunal ad-hoc se constituya en custodio de la caución, hasta que la acción de nulidad sea resuelta. Sin embargo, no existe una norma que sustente tal postura.

\subsection{La norma no señala el procedimiento para la devolución de la caución}

Sobre el tercer punto, tampoco existe un procedimiento en la Ley para la devolución de la caución. Sin embargo, en los reglamentos de varios centros de arbitraje, se encontró que éstos han tratado de buscar una forma de solucionar el tema. Como se ha

15. Reglamento Modelo del Instituto Ecuatoriano de Arbitraje, Art. 37.

16. Entre las facultades residuales de los árbitros y de los secretarios está la de conocer cualquier pedido de las partes que no pueda ser atendido por el centro de arbitraje, especialmente y con más frecuencia, en casos de arbitrajes independiente. En algunos casos los tribunales arbitrales han debido atender pedidos relativos a medidas cautelares ordenadas en el proceso arbitral, tiempo después de dictar el laudo arbitral. 
citado anteriormente, el Reglamento de Arbitraje del Centro de Arbitraje y Conciliación de la Cámara de Comercio de Guayaquil se limita a señalar en su artículo 26 que "[1]a caución se constituirá a favor de la Cámara de Comercio de Guayaquil, quien dispondrá su entrega a quien corresponda, una vez ejecutoriada la sentencia que resuelva la acción de nulidad"17.

Por su parte el Reglamento para el Funcionamiento del Centro de Arbitraje y Mediación de la Cámara de Comercio Ecuatoriana Americana establece en su artículo 66, lo siguiente: “La caución se constituirá a favor del vencedor del arbitraje y se entregará a la Cámara de Comercio Ecuatoriano Americana, quien dispondrá su entrega a quien corresponda, una vez ejecutoriada la sentencia que resuelva la acción de nulidad"18.

En ambos casos, la solución que han adoptado estos centros, es que la caución sea devuelta "a quien corresponda", una vez ejecutoriada la sentencia que resuelva la acción de nulidad. De lo referido resulta evidente que será al vencedor de la acción de nulidad a quien se le entregue la caución, ya sea que tenga la calidad de actor o demandado en dicho proceso, en otras palabras, si la corte acepta la acción de nulidad, se devuelve la caución a quien la consignó, y si la corte niega dicha acción, se la entrega a quien habría sufrido el daño por la demora en la ejecución del laudo. Sin embargo, las normas citadas no son expresas al respecto.

Siendo que hay otros centros de arbitraje ${ }^{19}$ que no cuentan con normas como la señalada, se puede llegar a la conclusión de que no existiría uniformidad en este criterio, lo cual genera una

17. Reglamento de Arbitraje del Centro de Arbitraje y Mediación de la Cámara de Comercio de Guayaquil, N. 14.

18. Reglamento para el Funcionamiento del Centro de Arbitraje y Mediación de la Cámara de Comercio Ecuatoriana Americana, Art. 66.

19. Cabe señalar que, aún cuando no contiene normas que regulan lo relativo a la caución, el Reglamento para el Funcionamiento del Centro de Arbitraje y Mediación de la Cámara de Comercio de Quito, en su artículo 91 señala: "En aquellos casos no previstos por este Reglamento, el Centro resolverá por analogía de acuerdo a las disposiciones de otros Centros de Arbitraje y Mediación para casos similares". Esta disposición, permite al centro mencionado, utilizar las normas de los reglamentos de otros centros relacionadas con la caución y de esa forma resolver cualquier vacío al respecto.

Reglamento para el Funcionamiento del Centro de Arbitraje y Mediación de la Cámara de Comercio de Quito, $<$ goo.gl/FeMwyX $>(06 / 8 / 2018)$. 
incertidumbre para el usuario del arbitraje. La situación es aún más grave cuando el arbitraje es independiente y no ha contado con la colaboración de ningún centro de arbitraje.

\subsection{El término para consignar la caución podría ser muy corto especialmente para entidades del sector público}

En lo que tiene que ver con el cuarto punto, relacionado con el tiempo que la Ley otorga para rendir la caución, es preciso señalar que este podría ser muy corto, sobre todo cuando en los arbitrajes participa una entidad del Estado, y la disponibilidad de los fondos requiere un trámite particular.

En efecto, tres días no es un tiempo suficiente para rendir una caución, en especial para las entidades públicas que deben cumplir con un proceso administrativo que podría llevar más tiempo que el previsto en la Ley. Si bien, se podría planificar y prever los fondos para rendir la caución, al no tener una regulación que establezca la forma en cómo debe calcularse su valor, la entidad o cualquier persona privada no sabrá el monto, sino hasta cuando el tribunal arbitral lo determine mediante providencia.

Lo dicho, puede llevar a que la entidad pública no cuente con el tiempo suficiente para rendir la caución correspondiente y por ello perder su derecho a suspender la ejecución del laudo arbitral.

En este punto, cabe señalar que los árbitros están impedidos por la existencia de una norma expresa a otorgar más tiempo para que la parte pueda rendir la caución. Un ejemplo de lo referido se encuentra, en el caso de nulidad No. 070-2014-17100, antes mencionado, en donde el tribunal arbitral dispuso:

[...] 3.- La accionante de la nulidad consignará en el término improrrogable de tres días, la caución señalada por este Tribunal, bajo prevenciones del Art. 31 de la Ley de Arbitraje y Mediación, puesto que, de no hacerlo, se remitirá el proceso 
a la Corte Provincial de Justicia, sin orden de suspensión de laudo arbitral $[\ldots]^{20}$.

Sin embargo de lo dicho, algunos tribunales arbitrales, cuando las partes solicitan una prórroga para rendir la caución, la han otorgado a fin de precautelar los derechos de las partes.

Visto lo señalado, resulta interesante valorar la posibilidad de una reforma a la Ley estableciendo: (i) un término mayor para rendir la caución; o, (ii) dejar en libertad a los árbitros la determinación del tiempo necesario para rendirla y la posibilidad de prorrogar dicho término ${ }^{21}$.

\section{ForMAS DE RENDIR CAUCIÓN}

En general, se utilizan tres formas de rendir caución. La primera es a través de la entrega de efectivo o de un cheque certificado de una institución financiera. La segunda forma de rendir caución es a través de la entrega de una garantía incondicional, irrevocable y de cobro inmediato, otorgada por una entidad financiera. Y, finalmente, se puede rendir caución a través de una póliza de seguro incondicional, e irrevocable, de cobro inmediato, emitida por una compañía de seguros.

Este criterio aparece en el artículo 66 del Reglamento para el Funcionamiento del Centro de Arbitraje de la Cámara de Comercio Ecuatoriano Americana, cuando dispone:

[...] Las cauciones que podrán rendirse son: 1. Garantía incondicional, irrevocable y de cobro inmediato, otorgada por un banco, o institución financiera, establecidos en el país o por intermedio de ellos; 2. Fianza instrumentada en una póliza de seguros, incondicional e irrevocable, de cobro inmediato, emi-

20. Laudo arbitral, N. 8.

21. El Reglamento Modelo propuesto por el Instituto Ecuatoriano de Arbitraje propone justamente que el tiempo para rendir la caución sea señalado libremente por los árbitros, pudiendo ser incluso prorrogado. Así, el artículo 37 plantea: “[...] 4. La caución deberá ser constituida en el término establecido por el Tribunal Arbitral para estos efectos. Este término podrá ser prorrogado a solicitud motivada de parte [...]". 
tida por una compañía de seguros establecida en el país; 3. Efectivo o Cheque Certificado de una institución financiera establecida en el país consignado en la Cámara de Comercio Ecuatoriano Americana, que deberá ser depositado en una cuenta de la misma $[\ldots]^{22}$.

Asimismo, el artículo 37 del Reglamento Modelo del Instituto Ecuatoriano de Arbitraje citado anteriormente dispone al respecto:

[...] 2. Las cauciones que podrán rendirse son: a. Garantía incondicional, irrevocable y de cobro inmediato, otorgada por un banco, o institución financiera, establecidos en el país o por intermedio de ellos; b. Fianza instrumentada en una póliza de seguros, incondicional e irrevocable, de cobro inmediato, emitida por una compañía de seguros establecida en el país; c. Efectivo o Cheque Certificado de una institución financiera establecida en el país consignado en la Cámara XX, que deberá ser depositado en una cuenta de la misma. 3. La caución se constituirá a favor del vencedor del arbitraje y se entregará a la Cámara XX, quien dispondrá su entrega a quien corresponda, una vez ejecutoriada la sentencia que resuelva la acción de nulidad. $[\ldots]^{23}$.

\subsection{Aspectos importantes a tener en cuenta respecto a las for- mas de rendir caución}

Se identifican tres elementos fundamentales que se deben tener en cuenta con relación a las formas de rendir caución descritas anteriormente, estos son disponibilidad inmediata, vigencia y efectividad independiente. A continuación se analizan estos aspectos.

22. Reglamento para el Funcionamiento del Centro de Arbitraje y Mediación de la Cámara de Comercio Ecuatoriana Americana, N. 18.

23. Reglamento Modelo del Instituto Ecuatoriano de Arbitraje, N. 15. 


\subsubsection{Disponibilidad inmediata}

Que la caución sea de disponibilidad inmediata significa que el medio que se utilice debe garantizar la posibilidad de acceder a la cantidad ordenada de manera efectiva y rápida. No parecería ser un problema pues, cuando se trata de dinero en efectivo, el Centro de Arbitraje no podría hacer uso de él y por lo tanto, lo tendrá disponible en la cuenta asignada para estos efectos, al momento en que la parte beneficiaria solicite su devolución. Asimismo, cuando se trata de garantías bancarias o pólizas de seguro, es importante que los fondos que estos documentos representan, estén disponibles tan pronto se los requiera.

\subsubsection{Vigencia}

Es indispensable que la caución se mantenga vigente hasta la ejecutoria del fallo que resuelva la acción de nulidad, pues caso contrario, cuando se la requiera, no podrá estar a disposición del centro de arbitraje, en el caso de un arbitraje administrado, o del tribunal arbitral independiente, en el caso de un arbitraje ad-hoc. Por lo dicho, la caución o específicamente el documento que la contenga, deberá tener el carácter de renovable automáticamente antes de su vencimiento, a petición y bajo responsabilidad de quien la rinde.

El artículo 31 de la Ley de Arbitraje y Mediación no determina quién debería hacer la renovación de los documentos, a saber: la parte que lo entregó o el Centro de Arbitraje, y tampoco señala la procedencia de una renovación automática.

El Reglamento para el Funcionamiento del Centro de Arbitraje de la Cámara de Comercio Ecuatoriano Americana señala que en caso de falta de renovación de la póliza, esta se efectivizará y la Cámara tendrá en custodia los fondos hasta cuando se resuelva la acción de nulidad ${ }^{24}$. Sin embargo, esta alternativa pare-

24. Reglamento del Centro de Arbitraje de la Cámara de Comercio Ecuatoriano Americana, Art. 66. $<$ https://www.ecamcham.com/Base_\%20Legal_CAM/Reglamento_para_el_funcionamiento_CAM.pd f> $(06 / 8 / 2018)$. 
cería obligar a que el documento tenga como beneficiaria a dicha Cámara y no a la parte que se vería perjudicada por la demora en la ejecución del laudo (vencedor del arbitraje), conforme lo establece el propio artículo 66 de su reglamento de funcionamiento en concordancia con el artículo 31 de la Ley de Arbitraje y Mediación. El Reglamento Modelo del Instituto Ecuatoriano de Arbitraje, en este punto sigue la línea del Reglamento del Centro de la Cámara de Comercio Ecuatoriano Americana ${ }^{25}$.

\subsubsection{Efectividad independiente}

Finalmente, la efectividad independiente de la caución significa que ésta no requiera del concurso de ninguna otra voluntad para hacerse efectiva. Así, la caución no puede estar condicionada a la voluntad de persona o ente alguno, o al cumplimiento de determinadas circunstancias, pues de ser ese el caso, eventualmente no estaría disponible. Por lo dicho, el acceso a la caución, debe ser libre de condición alguna, para que cumpla debidamente su finalidad y razón de ser.

\section{EJEMPLOS DE FÓRMULAS UTILIZADAS}

En el contexto de lo señalado anteriormente, resulta de gran interés revisar las fórmulas que utilizan en la práctica los tribunales arbitrales al momento de establecer, tanto la forma, como el monto de la caución, en los casos particulares que les corresponde. Así, a continuación se presentan a manera de ejemplo algunas decisiones al respecto emitidas por distintos tribunales arbitrales de Quito.

Art. 66. - “[...] La caución rendida deberá ser renovable automáticamente antes de su vencimiento o a la sola solicitud del Centro. De no ser renovada la caución esta se efectivizará y la Cámara tendrá los fondos disponibles hasta cuando se resuelva la acción de nulidad [...]".

25. Reglamento Modelo del Instituto Ecuatoriano de Arbitraje, N. 15, Art. 37.

Art. 37. - "[...] 5. La caución rendida deberá ser renovable automáticamente antes de su vencimiento o a la sola solicitud del Centro. De no ser renovada la caución esta se efectivizará y la Cámara tendrá los fondos disponibles hasta cuando se resuelva la acción de nulidad. [...]”. 
La fórmula que con más frecuencia se utiliza se evidencia de la siguiente manera: el valor de la caución corresponde al " $10 \%$ del valor ordenado a pagar, considerando el tiempo aproximado real que toma la tramitación de la acción de nulidad en la Corte Provincial" 26 .

Cabe señalar que algunos tribunales arbitrales utilizan para fijar el monto de la caución un análisis de perjuicios asimilable al cálculo de intereses. Esta fórmula resulta interesante pues considera los parámetros indicados anteriormente de tiempo y cuantía. Un caso concreto que ejemplifica esta posibilidad es el siguiente: la caución es el valor "equivalente al $4 \%$ de interés por un año, tiempo estimado para que concluya el proceso respectivo. La caución se mantendrá vigente hasta que se acepte finalmente la acción de nulidad o se haga efectiva por juez competente, al iniciarse el procedimiento de ejecución, de rechazarse la acción"27.

Siguiendo la misma idea, tenemos el siguiente ejemplo: la caución se fija al "aplicar la tasa de interés legal por 12 meses que podría demorar la ejecución del laudo"28.

En algunas ocasiones los árbitros no dan explicación respecto a la forma cómo se fija el monto de la caución, pero detallan los asuntos relacionados con la caución, como en el siguiente ejemplo:

2.- Con fundamento en el artículo 31 de la Ley de Arbitraje y Mediación, este Tribunal Arbitral dispone: 2.1.- Suspender la ejecución del laudo, para lo cual fija la cuantía de la caución que deberá rendir XXX a favor de XXX, en el valor de US\$ 1.908.57 (mil novecientos ocho 57/100 Dólares de los Estados Unidos de América); caución que deberá ser consignada en este Centro de Arbitraje y Mediación en el término de tres días, en una de las siguientes formas: a) garantía incondicional, irrevocable y de cobro inmediato, otorgada por una entidad financiera; b) póliza de seguro incondicional, e

26. Proceso arbitral No. 053-17.

27. Proceso arbitral No. 114-13.

28. Proceso arbitral No. 002-15. 
irrevocable, de cobro inmediato, emitida por una compañía de seguros; o, c) efectivo o cheque certificado de una institución financiera a órdenes del Centro de Mediación y Arbitraje de la Cámara de Comercio de Quito (o según haya establecido el Centro). La caución, en los casos a) y b) deberá mantenerse vigente hasta la ejecutoria del fallo que resuelva la acción de nulidad, por lo que deberá tener el carácter de renovable automáticamente antes de su vencimiento, a petición y bajo responsabilidad de XXX. 2.2.- Una vez constituida la caución a satisfacción del Tribunal y se disponga de la copia certificada del proceso, remítase el expediente al Presidente de la Corte Provincial de Justicia de Pichincha ${ }^{29}$.

Un ejemplo utilizado para establecer la caución en relación a obligaciones que son distintas al pago de un monto de dinero específico, tenemos el siguiente caso:

En vista de la petición de la demandada de que se suspenda la ejecución del laudo, en consideración de que el inciso tercero del citado artículo 31 de la Ley de Arbitraje y Mediación establece que tal suspensión se dispondrá siempre y cuando se caucionen los daños y perjuicios que la suspensión puede causar a la parte contraria y de que el principal daño que sufrirán las actoras, por tal suspensión, será la demora en la entrega del inmueble objeto del contrato, suspensión que impedirá su explotación por alrededor de dieciocho meses que suele tomar la tramitación de una acción de nulidad, en esta provincia, se fija en US \$ 14.400 la caución que debe rendir la demandada, que la mantendrá vigente hasta que se inicie la ejecución del laudo ${ }^{30}$.

\section{Problema: ¿Qué es "CAUCión Suficiente"?}

Como se ha dicho, el principal problema para los juzgadores, específicamente para los árbitros, está en establecer qué significa "caución suficiente". Los criterios de temporalidad y cuantía en ocasiones no reflejan ni la realidad, ni la justicia. De los ejemplos

29. Proceso arbitral No. 154-16.

30. Proceso arbitral No. 024-14. 
revisados se puede evidenciar que los árbitros se ven en la necesidad de estimar el tiempo que puede demorar la tramitación de la acción de nulidad, que como se ha dicho, es incierto, pues así como puede demorar seis meses, puede ser un año o más.

El problema planteado no es simple, considerando que existen derechos de las partes que pueden ser vulnerados con facilidad. Así, si el monto de la caución fijado es muy alto el accionante que tenga interés real y fundado para pedir la suspensión de la ejecución del laudo, puede verse en la imposibilidad de rendir la caución y esto afectar sus derechos, pues significaría una vulneración al derecho de tutela judicial efectiva. Y, por el otro lado, si se fija un monto de caución muy bajo, quien obtuvo laudo favorable puede quedar desprotegido cuando se fija una caución que no alcance a cubrir el daño potencial por el retardo en la ejecución.

Por lo dicho, parece que la solución para evitar la discrecionalidad en la forma de establecer el monto de la caución se podría solucionar si se provee de directrices a los árbitros, y en general a los juzgadores, para entender en qué rangos una caución es "suficiente". Así, si los juzgadores cuentan con reglas o guías, se estaría caminando hacia contar con seguridad jurídica en el tema y evitar la arbitrariedad. Esto nos lleva a la siguiente pregunta planteada en este análisis.

\section{7. ¿SE PUEDE REglamentar La FORMA EN CÓMO SE DEBE FIJAR LA CAUCIÓN?}

La pregunta que corresponde hacerse en este punto, a fin de buscar posibles soluciones a los problemas planteados, es si este tema es o no legislable o regulable a través de normas positivas. A fin de responder esta interrogante, en primer lugar, se debe tener en cuenta que el hecho de fijar la caución, no puede entenderse como una operación automática, pues evidentemente debe responder a un análisis de las circunstancias específicas del caso 
y ser el resultado de un proceso lógico, que debe ser individualizado y no genérico o aleatorio.

Con el fin de buscar una solución del tema a través de las normas positivas, se puede pensar en hacerlo a través de tres vías:

i. Una resolución por parte de la Corte Nacional de Justicia, en la cual se emita un instructivo con directrices básicas para jueces y árbitros. Al igual que lo hizo con el trámite de la acción de nulidad, la Corte Nacional de Justicia pueda emitir una resolución obligatoria, tanto para el tratamiento de la caución en la casación, como en el arbitraje. Una de las dificultades que podría enfrentar, siendo quizás la razón por la cual no lo ha hecho hasta ahora, es la dificultad intrínseca para fijar los parámetros que el monto de la caución representa;

ii. La inclusión en los reglamentos de los centros de arbitraje de parámetros mínimos suficientes de cómo establecer el monto de la caución. Como hemos visto, algunos centros han hecho lo posible por tratar de regular algunos aspectos relacionados con el tratamiento de la caución, sin embargo, no ha sido suficiente, quedando en manos de los árbitros tomar las decisiones al respecto. Considerando que en el Ecuador, en su mayoría, los arbitrajes son administrados, contar con reglas claras en los reglamentos de los centros podría ser de mucha utilidad y solucionar definitivamente el problema. Aún más, si en los arbitrajes ad-hoc se utilizan también estos reglamentos; $\mathrm{y}$,

iii. Por medio de una reforma legislativa, considerando que se encuentra en debate una reforma a la actual Ley de Arbitraje y Mediación, a la luz de la Ley Modelo CNUDMI ${ }^{31}$. Esta op-

31. La Ley Modelo CNUDMI no utiliza la palabra caución, sino "garantía” y en su artículo 35 dispone al respecto lo siguiente: "[...] 2) Si se ha pedido a un tribunal de los previstos en el inciso v) del apartado a) del párrafo 1) del presente artículo la nulidad o la suspensión del laudo, el tribunal al que se pide el reconocimiento o la ejecución podrá, si lo considera procedente, aplazar su decisión y, a instancia de la parte que pida el reconocimiento o la ejecución del laudo, podrá también ordenar a la otra parte que dé garantías apropiadas. [...]". Es claro que la Ley Modelo no trae luces al respecto, pues contiene una norma demasiado general, por lo que cualquier reforma debe ir más allá sobre el punto de la caución.

Ley Modelo CNUDMI, Art. 35(2), <goo.gl/j2cfFj> (06/08/2018). 
ción parece ser la más complicada, sin embargo, de lograrse un tratamiento legislativo a este tema, sería importante al menos definir cuáles serían los parámetros propuestos para la reforma. Quizá podría incluirse, siguiendo la línea de lo que ha sido aceptado hasta ahora, se fije la caución, atendiendo al tiempo que la propia ley establezca para resolver la acción de nulidad y la tasa de interés legal calculado sobre la cuantía de la condena. Considerando la resolución sobre el trámite de la acción de nulidad emitida por la Corte Nacional de Justicia y la oralidad en los procesos, podría ser interesante que en la reforma se incluya que esta acción sea resuelta en un término no mayor a noventa días. Adicionalmente, se debe tener en cuenta que la fórmula a utilizarse sea útil para casos donde la condena es declarativa o no se pueda valorar en dinero, además de que se puede pensar en la posibilidad de que la Corte revise la decisión que sobre el monto haya tomado el tribunal arbitral, como lo plantea la norma correspondiente peruana ${ }^{32}$.

Mientras no haya una regulación clara sobre la forma en que debe fijarse la caución, los árbitros continuarán con esta tarea, y

32. Decreto Legislativo No. 1071 de la República del Perú, Art. 66. "Garantía de cumplimiento. 1. La interposición del recurso de anulación no suspende la obligación de cumplimiento del laudo ni su ejecución arbitral o judicial, salvo cuando la parte que impugna el laudo solicite la suspensión y cumpla con el requisito de la garantía acordada por las partes o establecida en el reglamento arbitral aplicable. Al examinar la admisión del recurso, la Corte Superior verificará el cumplimiento del requisito y, de ser el caso, concederá la suspensión. 2. Si no se ha acordado requisito alguno, a pedido de parte, la Corte Superior concederá la suspensión, si se constituye fianza bancaria solidaria, incondicionada y de realización automática en favor de la otra parte con una vigencia no menor a seis (6) meses renovables por todo el tiempo que dure el trámite del recurso y por una cantidad equivalente al valor de la condena contenida en el laudo. 3. Si la condena, en todo o en parte, es puramente declarativa o no es valorizable en dinero o si requiere de liquidación o determinación que no sea únicamente una operación matemática, el tribunal arbitral podrá señalar un monto razonable en el laudo para la constitución de la fianza bancaria en las mismas condiciones referidas en el numeral anterior, como requisito para disponer la suspensión de la ejecución, salvo acuerdo distinto de las partes. 4. La parte impugnante podrá solicitar la determinación del monto de la fianza bancaria prevista en el numeral anterior a la Corte Superior que conoce del recurso, cuando el tribunal arbitral no lo hubiera determinado. También podrá solicitar su graduación, cuando no estuviere de acuerdo con la determinación efectuada por el tribunal arbitral. La Corte Superior luego de dar traslado a la otra parte por tres (3) días, fijará el monto definitivo en decisión inimpugnable. 5. La garantía constituida deberá renovarse antes de su vencimiento mientras se encuentre en trámite el recurso, bajo apercibimiento de ejecución del laudo. Para tal efecto, la Corte Superior, a pedido de la parte interesada, de ser el caso, oficiará a las entidades financieras para facilitar la renovación. 6. Si el recurso de anulación es desestimado, la Corte Superior, bajo responsabilidad, entregará la fianza bancaria a la parte vencedora del recurso. En caso contrario, bajo responsabilidad, lo devolverá a la parte que interpuso el recurso. 
su decisión al respecto, como todas aquellas que emitan durante un proceso, deberá estar debidamente motivada, más aun considerando que no existe una normativa que sustente tal decisión. Es decir, el tribunal arbitral deberá explicar claramente a las partes, cuáles fueron las directrices que utilizó para fijar el monto de la caución. Si bien, como se ha señalado, la norma apenas proporciona un solo parámetro -el perjuicio que la demora en la ejecución pueda provocar-, esto no justifica que los árbitros omitan explicar fehacientemente como llegaron al monto de la caución. La falta de motivación al respecto afecta directamente el derecho constitucional de las partes. Un ejemplo de ello, es aquel caso descrito en líneas anteriores en donde un tribunal arbitral conformado en un Centro de Arbitraje de Esmeraldas, decidió sin motivación alguna que el valor de la caución sería exactamente igual al valor al cual fue condenado a pagar una de las partes.

\section{Conclusiones}

La falta de normativa, o al menos de una guía básica que facilite a los juzgadores la tarea de fijar la forma y el monto a fin de que las partes rindan caución en los casos que se requiera, ha dado como resultado afectaciones a la seguridad jurídica, por la inevitable discrecionalidad y posible arbitrariedad en el tema. Se identifican al menos los siguientes problemas: (i) la norma no establece la forma en que debe calcularse el monto de la caución; (ii) no se establece con claridad donde se debe consignar la caución especialmente en un arbitraje independiente; (iii) la norma no señala el procedimiento para la devolución de la caución; y, (iv) el término para consignar la caución podría ser muy corto especialmente para entidades del sector público.

Con el fin de abrir el debate sobre la posibilidad de reglamentar lo concerniente a la fijación de la caución, se plantean los aspectos más importantes a tener en cuenta, considerando que ésta no puede ser el resultado de una operación automática, sino que 
debe analizar las circunstancias específicas del caso, y permitir cierta flexibilidad al juzgador.

En este contexto, se debe considerar que, a fin de señalar el monto de la caución, los parámetros a tener presente son el tiempo y el monto de la condena; y sobre la forma de rendirla, los aspectos fundamentales son disponibilidad inmediata, vigencia y efectividad independiente.

No resulta fácil determinar qué significa "caución suficiente" conforme lo previsto en la ley, por lo que resulta indispensable una reglamentación suficiente al respecto. 